Proceeding

Oopen Access

CrossMark

\title{
Effect of music on the quality of life of turkish cochlear implant users: a focus group study
}

\begin{abstract}
Objective: To study the effect of music on the quality of life (QoL) in postlingual and prelingual adult cochlear implant (CI) users.

Methods: Thirty adult CI users aged between 18 and 50years old with non-musical backgrounds participated in the study. ${ }^{1-5}$ Five focus group discussions about music in everyday life were conducted and data were analyzed using template analysis based on the QoL model of the World Health Organisation Quality of Life BREF questionnaire.

Results and discussion: A theoretical framework of the impact of music on the QoL was developed. Music was reported to contribute to many aspects of physical, psychological, and social well-being in adult CI users. ${ }^{5-10}$ These positive effects of music on QoL were similar to what has been reported in the literature for normal-hearing adults. However, difficulties in music perception and enjoyment were found to have a negative impact on $\mathrm{CI}$ users' QoL, especially by causing unpleasant feelings and limited participation in musicrelated or routine daily activities.

Conclusion: Adult CI users face difficulties in perceiving and enjoying music that prevent them from participating in music activities when compared with NH adults. Therefore, this situation has a negative impact on CI users' physical, psychological and social wellbeing. The optimization of listening to and enjoyment of music for CI users can have positive effect on their QoL. ${ }^{10-14}$ The findings are of clinical significance as they stress the value of improving the music experience of adult $\mathrm{CI}$ users through new music-focused $\mathrm{CI}$ technologies or music auditory training.
\end{abstract}

Volume 9 Issue 3 - 2017

\author{
Merve Torun Topcu, Birgul Gumus, Ayca \\ Ciprut \\ Marmara University, Turkey
}

Correspondence: Merve Torun Topcu Marmara University Fevzi Cakmak Mahallesi Muhsin Yazicioglu Cd No 1034899 Pendik Istanbul, Turkey, Tel 53|2078067, Email tugba.merve.torun@hotmail.com

Received: November 27, 2017 | Published: November 28, 2017

\section{Acknowledgments}

None.

\section{Conflicts of interest}

Author declares there are no conflicts of interest.

\section{Funding}

None.

\section{References}

1. Bartel LR, Greenberg S, Friesen LM, et al. Qualitative case studies of five cochlear implant recipients' experience with music. Cochlear Implants Int. 2011;12(1):27-33.

2. TanChyuan C, Nikki SR. The Music USE (MUSE) questionnaire: an instrument to measure engagement in music. Music Perception: $A n$ Interdisciplinary Journal. 2012;29(4):429-446.

3. Cooke M, Moyle W, Shum D, et al. A randomized controlled trial exploring the effect of music on quality of life and depression in older people with dementia. J Health Psycho. 2010;15(5):765-776.

4. Drennan WR, Oleson JJ, Gfeller K, et al. Clinical evaluation of music perception, appraisal and experience in cochlear implant users. Int $J$ Audiol. 2015;54(2):114-123.

5. Erkkilä J, Punkanen M, Fachner J, et al. Individual music therapy for depression: randomised controlled trial. $\mathrm{Br} J$ Psychiatry. 2011;199(2):132-139.
6. Fuller C, Mallinckrodt L, Maat B, et al. Music and quality of life in earlydeafened late-implanted adult cochlearimplantusers. Otol Neurotol. 2013;34(6):1041-1047.

7. Krueger RA, Casey MA. Focusgroups: A practical guide for applied research. 2015.

8. Leigh JR, Moran M, Hollow R, et al. Evidence based guidelines for recommending cochlear implantation for postlingually deafened adults. Int $J$ Audiol. 2016;55(Suppl 2):S3-S8.

9. Migirov L, Kronenberg J, Henkin Y. Self-reported listening habits and enjoyment of music among adult cochlear implant recipients. Ann Otol Rhinol Laryngol. 2009;118(5):350-355.

10. Dritsakis G, van Besouw RM, O' Meara A. Impact of music on the quality of life of cochlear implant users: a focus group study. Cochlear Implants Int. 2017;18(4):207-215.

11. Moran M, Rousset A, Looi V. Musicappreciationandmusic listening in prelingual and postlingually deaf adult cochlear implant recipients. Int $\mathrm{J}$ Audiol . 2016;55(Suppl 2):S57-S63.

12. Skevington SM, Lotfy M, O'Connell KA. The World Health Organization's WHOQOL-BREF quality of life assessment: psychometric properties and results of the international field trial. A report from the WHOQOL Group. Qual Life Res. 2004;13(2):299-310.

13. Sladen DP, Zappler A. Older and younger adult cochlear implant users: speech recognition in quiet and noise, quality of life, and music perception. American Journal of Audiology. 2015;24:31-39.

14. WHOQOL. Study protocol for the World Health Organization project to develop a Quality of Life assessment instrument (WHOQOL). Qual Life Res. 1993;2(2):153-159. 